\title{
Comparison between FOLFIRINOX and gemcitabine plus nab-paclitaxel including sequential treatment for metastatic pancreatic cancer: a propensity score matching approach
}

Jung Won Chun', Sang Hyub Lee ${ }^{2^{*}}$ (D) Joo Seong Kim², Namyoung Park², Gunn Huh², In Rae Cho², Woo Hyun Paik², Ji Kon Ryu ${ }^{2}$ and Yong-Tae Kim²

\begin{abstract}
Background: FOLFIRINOX (FFX) and Gemcitabine plus nab-paclitaxel (GnP) have been recommended as the firstline chemotherapy for metastatic pancreatic cancer (mPC). However, the evidence is lacking comparing not only two regimens, but also sequential treatment (FFX-GnP vs. GnP-FFX).

Methods: Data of 528 patients (FFX, $n=371 ; G n P, n=157$ ) with mPC were collected retrospectively. Propensity score matching was conducted to alleviate imbalance of the two groups. Overall survival (OS), progression free survival (PFS), and toxicity of patients were analyzed.
\end{abstract}

Results: In the whole population, OS (12.5 months vs. 10.3 months, $P=0.05)$ and PFS (7.1 months vs. 5.8 months, $P=0.02$ ) were longer in the FFX group before matching and after matching (OS: 11.8 months vs. 10.3 months, $P=$ 0.02; PFS: 7.2 months vs. 5.8 months, $P<0.01$ ). For sequential treatment, OS and PFS showed no significant difference. Interruptions of chemotherapy due to toxicities were more frequent ( $6.8 \mathrm{vs.} 29.3 \%, P<0.001)$ in the GnP group, and cessation of chemotherapy showed a significant association with mortality $(z=-1.94, P=0.03)$.

Conclusions: FFX achieved a longer overall survival than GnP in $\mathrm{MPC}$, but not in the comparison for sequential treatment. More frequent adverse events followed by treatment interruptions during GnP might lead to a poor survival outcome. Therefore, FFX would be a better first-line treatment option than GnP for MPC.

Keywords: Pancreatic neoplasms, Folfirinox, Albumin-bound paclitaxel, Survival

\footnotetext{
* Correspondence: gidoctor@korea.com

${ }^{2}$ Department of Internal Medicine and Liver Research Institute, Seoul

National University Hospital, Seoul National University College of Medicine,

Seoul, South Korea

Full list of author information is available at the end of the article
}

(c) The Author(s). 2021 Open Access This article is licensed under a Creative Commons Attribution 4.0 International License, which permits use, sharing, adaptation, distribution and reproduction in any medium or format, as long as you give appropriate credit to the original author(s) and the source, provide a link to the Creative Commons licence, and indicate if changes were made. The images or other third party material in this article are included in the article's Creative Commons licence, unless indicated otherwise in a credit line to the material. If material is not included in the article's Creative Commons licence and your intended use is not permitted by statutory regulation or exceeds the permitted use, you will need to obtain permission directly from the copyright holder. To view a copy of this licence, visit http://creativecommons.org/licenses/by/4.0/ The Creative Commons Public Domain Dedication waiver (http://creativecommons.org/publicdomain/zero/1.0/) applies to the data made available in this article, unless otherwise stated in a credit line to the data. 


\section{Background}

Pancreatic cancer (PC) is the seventh leading cause of cancer deaths worldwide. It is predicted to be the second-leading cause of cancer death in the USA by 2030 [1, 2]. Patients with PC have a poor prognosis, with a 5 -year survival rate of $9 \%$. Only less than $20 \%$ of patients with PC are resectable at initial diagnosis [2]. Most patients are diagnosed in an advanced stage. Chemotherapy is the mainstay treatment strategy for unresectable pancreatic cancer. However, options of chemotherapeutic regimen are still limited and some of them are often ineffective. Since single-agent gemcitabine was introduced as an effective treatment option in 1997, combination regimens are currently considered to be superior to monotherapy for advanced pancreatic cancer [3, 4]. It has been demonstrated that FOLFIRINOX (FFX, a combination of 5 -fu, leucovorin, irinotecan, and oxaliplatin) and gemcitabine plus nab-paclitaxel (GnP) can significantly improve response rates and survival benefits compared to gemcitabine only in the randomized phase III PRODIGE and MPACT trials, respectively $[5,6]$. Therefore, these two combination regimens are now recommended as first-line treatment for metastatic pancreatic cancer (mPC) [7-9].

There is no prospective study comparing FFX to GnP directly in mPC. Although the median survival of $\mathrm{GnP}$ is numerically shorter ( 8.5 months vs. 11.1 months) than FFX in those landmark trials, proportions of elderly patients, tumor burden, and patients with Eastern Cooperative Oncology Group performance status (ECOGPS) 2 were higher in the MPACT trial [10]. Differences in enrolled population and study design make it difficult to directly compare their efficacy outcomes. In a realworld retrospective data of patients with advanced pancreatic cancer, two regimens showed comparable efficacy in terms of overall survival (OS) and progression free survival (PFS) [11]. And a recent meta-analysis including 16 retrospective or cohort studies also reported no major benefit of FFX in survival or response rate [12].

The survival benefit of FFX and GnP has been demonstrated and approximately half of patients with advanced pancreatic cancer receive second-line treatment [10]. Maintaining effective treatment for as long as possible is an important issue for patients with advanced pancreatic cancer which showed poor overall survival. Therefore, it is necessary to consider the subsequent chemotherapy when selecting the first-line chemotherapy regimen. In $\mathrm{mPC}$, both FFX and GnP are available as second-line treatment option after progression on each exchanged regimen. However, the evidence for the effect of treatment sequence on OS is lacking. Therefore, the aim of this study was to compare the efficacy between FFX and $\mathrm{GnP}$ as well as their sequential treatment (FFX-GnP vs. GnP-FFX) in $\mathrm{mPC}$ in real world practice.

\section{Methods}

\section{Study population}

Patients who received FFX or $\mathrm{GnP}$ as first-line chemotherapy for $\mathrm{mPC}$ or recurrent $\mathrm{PC}$ after curative-intent resection at a tertiary university hospital in Korea between May 2011 and March 2019 were retrospectively reviewed in this study. Eligible patients were: (i) over 19 years old; (ii) pathologically confirmed pancreatic ductal adenocarcinoma; (iii) measurable disease according to the Response Evaluation Criteria in Solid Tumors, version 1.1; (iv) and ECOG-PS 2 or less. Patients who were lost to follow-up without initial tumor response evaluation were excluded. Data about patient's age, sex, laboratory finding, tumor size, tumor location, and image findings were retrospectively collected from the electronic medical records system. The cut-off date for data analysis was June 30, 2020. Information on survival data was obtained from the Ministry of the Interior and Safety in Korea. This study was approved by the Institutional Review Board of Seoul National University Hospital (IRB No. C-2009-058-1155). It was conducted in accordance with the Declaration of Helsinki.

\section{Chemotherapy regimens and response evaluation}

FFX was administered in combination with oxaliplatin $\left(85 \mathrm{mg} / \mathrm{m}^{2}\right)$, leucovorin $\left(400 \mathrm{mg} / \mathrm{m}^{2}\right)$, irinotecan $(180$ $\mathrm{mg} / \mathrm{m}^{2}$ ), and 5 -FU $\left(400 \mathrm{mg} / \mathrm{m}^{2}\right.$ bolus, $2400 \mathrm{mg} / \mathrm{m}^{2}$ continuous infusion) via intravenous route every 2 weeks [5]. GnP regimen consisting of gemcitabine $(1000 \mathrm{mg} /$ $\left.\mathrm{m}^{2}\right)$ and nab-paclitaxel $\left(125 \mathrm{mg} / \mathrm{m}^{2}\right)$ was administered on days 1,8 , and 15 every 4 weeks [6]. Dose reduction (by $10-30 \%$ of one or more drug) or schedule adjustment were performed in consideration of individual patient's general condition and toxicities at the discretion of the clinician.

To evaluate treatment response, contrast enhanced computed tomography or magnetic resonance imaging was performed every 8 weeks. It was judged by the clinician according to the Response Evaluation Criteria in Solid Tumors. The detailed schedule of imaging studies was adjusted based on the patient's symptoms and laboratory findings. Treatment-related adverse events (AEs) were evaluated and graded in accordance with the Common Terminology Criteria for Adverse Events, version 4.0. Chemotherapy-induced peripheral neuropathy was assessed based on the requirement for antineuropathic drugs (pregabalin, carbamazepine, and gabapentin) or chemotherapy dose reduction due to neuropathic symptoms.

\section{Objectives and statistical analyses}

The primary objective was to compare OS and PFS between FFX and GnP according to their sequence. A propensity score matching (PSM) was used to alleviate the 
difference in baseline characteristics between the two groups of the study population. OS was defined as the time from the date of starting the first-line chemotherapy to the date of death or the last follow-up. PFS was defined as the time from the date of starting the firstline chemotherapy until the diagnosis of disease progression, death of any cause, or the last follow-up. PFS of sequential treatment was defined as the time between the first-line treatment and the second progression (progression after second-line treatment). Objective response rate (ORR) was defined as the percentage of patient with complete response or partial response. Disease control rate (DCR) was defined as ORR plus the rate of stable disease.

To estimate the propensity score, we used logistic regression including the following covariates: age, sex, ECOG-PS, number of metastatic sites, liver metastases, peritoneal seeding, lung metastases, previous curative pancreatic resection, location of primary tumor, and laboratory findings of baseline white blood cell counts and hemoglobin $(\mathrm{Hb})$ levels. We matched the two groups of patients using a one-to-one nearest-neighbor matching protocol without replacement with a caliper width of 0.1 [13]. Standard mean differences were indicated before and after PSM.

Categorical data are expressed as count (percentage). Continuous data are expressed as median (interquartile range, IQR). Continuous variables were compared by independent student's $t$-analysis. Non-continuous variables were compared by Chi-square or Fisher's exact test. Median follow-up was calculated using the reverse KaplanMeier method [14]. Survival was estimated using the Kaplan-Meier method and compared by log-rank test. Factors affecting survival were determined by Cox proportional hazard regression model including as follows: age $\geq 65$ years, sex, ECOG-PS $\geq 1$, presence of number of metastatic sites $\geq 2$, liver metastases, peritoneal seeding, and chemotherapy regimen identified as prognostic factors of survival in previous and present studies $[15,16]$. A $P$ value $<0.05$ was considered statistically significant. All statistical analyses were performed using SAS systems version 9.2 (SAS Institute, Inc., Cary, NC, USA) and SPSS 24.0 statistical software (SPSS Inc., Chicago, IL, USA).

\section{Results}

Patient characteristics in the whole population and matched population

A total of 528 patients who were treated with FFX (371 patients) or GnP (157 patients) as the first-line chemotherapy were included in the final analysis. Baseline characteristics of these patients are presented in Table 1 . Patients in the FFX group were significantly younger (61 years vs. 64 years, $P<0.001$ ) than those in the GnP group. However, ECOG-PS was not significantly different $(P=0.15)$ between the two groups. Recurrent pancreatic cancer after curative surgery was more frequent in the $\mathrm{GnP}$ group $(25.5 \%$ vs. $17.3 \%, P=0.03)$. The median time to recurrence was 7.8 months (IQR: $4.0-18.3$ months). There was no significant difference in tumor size, primary tumor location, or number of metastatic sites between the two groups. Peritoneal seeding $(P=$ $0.03)$ and lung metastases $(P=0.02)$ were more common in the GnP group. The median $\mathrm{Hb}$ level was higher in the $\mathrm{GnP}$ group $(12.5 \mathrm{~g} / \mathrm{dL}$ vs. $12.2 \mathrm{~g} / \mathrm{dL}, P=0.03)$, although the numerical difference did not seem to be significant. After PSM, there were no significant difference in baseline characteristics (median age, level of $\mathrm{Hb}$, proportion of previous curative surgery, peritoneal seeding, or lung metastases) between the two groups (Table 1).

\section{Treatment efficacy of FOLFIRINOX and gemcitabine plus nab-paclitaxel}

During the median follow-up period of 33 months, $83 \%$ patients (438 in the whole population; and 251 in the matched population) died after palliative chemotherapy. Detailed treatment data are presented in Table 2. In the first-line treatment setting, the median number of cycles of chemotherapy was 9 (IQR: 4-15) in the FFX group and 5 (IQR: 3-8) in the GnP group. Regardless of matching, the median treatment duration was significantly longer in the FFX group (5.6 months vs. 4.3 months, $P=0.03$ in the whole population; 5.9 vs. 4.3 months, $P=0.01$ in the matched population). In the FFX group, dose modification occurred more frequently $(46 \%$ vs. $36 \%, P=0.03$ before matching; $50 \%$ vs. $34 \%, P=0.01$ after matching) during treatment, while interruption of chemotherapy (cessation or changing the regimen) was less frequent ( $7 \%$ vs. $29 \%$ in the whole population; $8 \%$ vs. $23 \%$ in the matched population; both $P<0.001$ ) compared with the $\mathrm{GnP}$ group. Cessation chemotherapy among interruptions was significantly associated with more deaths $(P=0.03$ by $\mathrm{z}$-test; $\mathrm{z}=-1.94)$.

In terms of treatment efficacy, response rates were not significantly different between the two groups before PSM ( $30 \%$ vs. $32 \%, P=0.58)$ or after PSM ( $34 \%$ vs. $32 \%, P=$ 0.77). The median PFS was significantly longer in the FFX group both before PSM (7.1 months vs. 5.8 months, $P=$ $0.02)$ and after PSM (7.2 months vs. 5.8 months, $P<0.01$ ) compared to that in the GnP group (Fig. 1). In the whole population, FFX regimen showed a marginal benefit in the OS (12.5 months vs. 10.3 months, $P=0.05$ ) (Fig. 2). Statistical significance of survival benefit was further guaranteed after PSM (11.8 vs. 10.3 months, $P=0.02$ ). In multivariable adjusted analyses, survival benefit of FFX was supported, with hazard ratio (HR) of 0.80 (95\% confidence interval [CI]: $0.65-0.98 ; P=0.03$ ) before matching and $\mathrm{HR}$ of 0.74 (95\% CI: $\quad 0.57-0.95 ; \quad P=0.02) \quad$ after matching 
Table 1 Baseline characteristics of the population before and after propensity score matching

\begin{tabular}{|c|c|c|c|c|c|c|c|c|}
\hline & \multicolumn{4}{|c|}{ Whole study population } & \multicolumn{4}{|c|}{ Matched population } \\
\hline & $\begin{array}{l}\text { FOLFIRINOX } \\
(n=371)\end{array}$ & $\begin{array}{l}\text { Gemcitabine/nab- } \\
\text { paclitaxel }(n=157)\end{array}$ & $\begin{array}{l}P \\
\text { value }\end{array}$ & $\overline{S M D}$ & $\begin{array}{l}\text { FOLFIRINOX } \\
(n=151)\end{array}$ & $\begin{array}{l}\text { Gemcitabine/nab- } \\
\text { paclitaxel }(n=151)\end{array}$ & $\begin{array}{l}P \\
\text { value }\end{array}$ & SMD \\
\hline Age (years) & $61(54-67)$ & $64(57-71)$ & $\begin{array}{l}< \\
0.001\end{array}$ & 0.38 & $62(57-70)$ & $64(57-70)$ & 0.39 & 0.05 \\
\hline Sex, male & $229(61.7)$ & $94(59.9)$ & 0.69 & 0.04 & $84(55.6)$ & $91(60.3)$ & 0.42 & $\overline{-} .09$ \\
\hline ECOG-PS & & & 0.15 & -0.07 & & & 0.90 & 0.03 \\
\hline 0 & $64(17.3)$ & $34(21.7)$ & & & $33(21.9)$ & $32(21.2)$ & & \\
\hline 1 & $305(82.2)$ & $120(76.4)$ & & & $116(76.8)$ & $116(76.8)$ & & \\
\hline 2 & $2(0.5)$ & $3(1.9)$ & & & $2(1.3)$ & $3(2.0)$ & & \\
\hline Tumor size ${ }^{a}$ & $3.7(3.0-4.8)$ & $4.0(2.6-5.3)$ & 0.41 & 0.09 & $4.0(3.0-4.8)$ & $3.9(2.5-5.0)$ & 0.92 & 0.02 \\
\hline Tumor location ${ }^{a}$ & & & 0.07 & -0.06 & & & 0.63 & -0.01 \\
\hline Head/uncinate & $115(37.5)$ & $33(28.2)$ & & & 37 (31.9) & $33(28.9)$ & & \\
\hline Body/tail & $192(62.5)$ & $84(72.4)$ & & & $79(68.1)$ & $81(71.1)$ & & \\
\hline $\begin{array}{l}\text { Previous curative } \\
\text { surgery }\end{array}$ & $64(17.3)$ & $40(25.5)$ & 0.03 & 0.19 & $35(23.2)$ & $37(24.5)$ & 0.79 & 0.03 \\
\hline $\begin{array}{l}\text { Number of } \\
\text { metastatic sites }\end{array}$ & & & 0.15 & 0.09 & & & 0.78 & -0.07 \\
\hline 1 & $233(62.8)$ & $97(61.8)$ & & & $88(58.3)$ & $94(62.3)$ & & \\
\hline 2 & $97(26.1)$ & $34(21.7)$ & & & $37(24.5)$ & $33(21.9)$ & & \\
\hline 3 or more & $41(11.1)$ & $26(16.6)$ & & & $26(17.2)$ & $24(15.9)$ & & \\
\hline \multicolumn{9}{|l|}{ Metastatic sites } \\
\hline Liver metastases & $234(63.1)$ & $90(57.3)$ & 0.20 & -0.12 & $88(58.3)$ & 87 (57.6) & 0.91 & -0.01 \\
\hline $\begin{array}{l}\text { Peritoneal } \\
\text { seeding }\end{array}$ & $100(27.0)$ & $57(36.3)$ & 0.03 & 0.19 & $53(35.1)$ & $53(35.1)$ & 1 & 0 \\
\hline Lung metastases & $59(15.9)$ & $38(24.2)$ & 0.02 & 0.19 & $35(23.2)$ & $35(23.2)$ & 1 & 0 \\
\hline $\begin{array}{l}\text { Distant lymph } \\
\text { node }\end{array}$ & $125(33.7)$ & $51(32.5)$ & 0.79 & -0.03 & $51(33.8)$ & $49(32.5)$ & 0.81 & -0.03 \\
\hline $\begin{array}{l}\text { Other (bone, } \\
\text { adrenal) }\end{array}$ & $38(10.2)$ & $22(14.0)$ & 0.20 & 0.11 & $16(10.6)$ & $20(13.2)$ & 0.48 & 0.08 \\
\hline \multicolumn{9}{|l|}{ Laboratory findings } \\
\hline WBC (cells/uL) & $6.8(5.6-8.7)$ & $6.6(5.1-8.4)$ & 0.22 & -0.09 & $6.8(5.6-8.4)$ & $6.6(5.1-8.4)$ & 0.687 & -0.05 \\
\hline $\mathrm{Hb}(\mathrm{g} / \mathrm{dL})$ & $12.5(11.3-13.7)$ & $12.2(11.1-13.1)$ & 0.03 & -0.19 & $12(11-13)$ & $12(11-13)$ & 0.583 & 0.09 \\
\hline $\begin{array}{l}\text { PLT }(\times 103 \text { cells/ } \\
\text { uL) }\end{array}$ & $233(185-286)$ & $226(182-287)$ & 0.49 & -0.04 & 235 (189-287) & $224(180-287)$ & 0.338 & -0.09 \\
\hline Bilirubin (mg/dL) & $0.6(0.4-0.9)$ & $0.6(0.5-0.8)$ & 0.28 & -0.07 & $0.6(0.4-1.0)$ & $0.6(0.5-0.8)$ & 0.873 & -0.07 \\
\hline ALP (IU/L) & $82(68-146)$ & $89(72-123)$ & 0.45 & -0.06 & $88(66-130)$ & $89(72-123)$ & 0.874 & -0.01 \\
\hline Albumin (g/dL) & $3.9(3.6-4.2)$ & $4.0(3.7-4.2)$ & 0.50 & 0.02 & $3.9(3.6-4.2)$ & $4.0(3.7-4.2)$ & 0.195 & 0.09 \\
\hline CA 19-9 (U/mL) & $1010(121-5710)$ & $938(115-5320)$ & 0.80 & -0.54 & $676(58-4560)$ & $937(115-5740)$ & 0.481 & -0.02 \\
\hline
\end{tabular}

FFX folfirinox, GnP gemcitabine plus nab-paclitaxel, SMD standardized mean difference, ECOG-PS Eastern Cooperative Oncology Group performance status, WBC white blood cell count, $H b$ hemoglobin, PLT platelet count, ALP alkaline phosphatase, CA carbohydrate antigen

${ }^{a}$ Excluding previous curative resection cases

(Supplementary Table 1). Additionally, age above 65 years, liver metastases, and peritoneal seeding were independently associated with poor survival. In subgroup survival analyses, patients with younger age ( $<65$ years), ECOG-PS $1+$, and without history of previous pancreatic surgery showed statistically significant survival benefits with the FFX treatment (Supplementary Fig. 1-4).

\section{Sequential treatments of FOLFIRINOX (FFX-GnP) and gemcitabine plus nab-paclitaxel (GnP-FFX)}

Regimens of second-line chemotherapy are summarized in Table 2. The proportion of patients who received subsequent chemotherapy beyond first-line therapy was significantly higher in the FFX group than in the GnP group ( $69 \%$ vs. $59 \%$ before matching; $72 \%$ vs. $58 \%$ after 
Table 2 Detailed treatment data according to first-line chemotherapy regimen

\begin{tabular}{|c|c|c|c|c|c|c|}
\hline & \multicolumn{3}{|c|}{ Whole study population } & \multicolumn{3}{|c|}{ Matched population } \\
\hline & $\begin{array}{l}\text { FOLFIRINOX } \\
(n=371)\end{array}$ & $\begin{array}{l}\text { Gemcitabine/nab- } \\
\text { paclitaxel }(n=157)\end{array}$ & $P$ value & $\begin{array}{l}\text { FOLFIRINOX } \\
(n=151)\end{array}$ & $\begin{array}{l}\text { Gemcitabine/nab- } \\
\text { paclitaxel }(n=151)\end{array}$ & $\begin{array}{l}P \\
\text { value }\end{array}$ \\
\hline $\begin{array}{l}\mathrm{N} \text { of cycle during first-line } \\
\text { chemotherapy }\end{array}$ & $9(4-15)$ & $5(3-8)$ & & $9(4-15)$ & $5(3-8)$ & - \\
\hline $\begin{array}{l}\text { Treatment duration of first-line } \\
\text { (months) }\end{array}$ & $5.6(1.8-9.8)$ & $4.3(2.3-7.0)$ & 0.03 & $5.9(2.2-10.1)$ & $4.3(2.2-6.9)$ & 0.01 \\
\hline $\begin{array}{l}\text { Dose reduction during first-line } \\
\text { chemotherapy }\end{array}$ & $172(46.4)$ & $57(36.3)^{a}$ & 0.03 & $76(50.3)$ & $52(34.4)^{a}$ & 0.01 \\
\hline $\begin{array}{l}\text { Interruption }{ }^{\mathrm{b}} \text { chemotherapy due } \\
\text { to AEs }\end{array}$ & $25(6.8)$ & $46(29.3)$ & $<0.001$ & $12(7.9)$ & $35(23.1)$ & $\begin{array}{l}< \\
0.001\end{array}$ \\
\hline Cessation treatment & $21(5.7)$ & $24(15.3)$ & & $11(7.3)$ & $28(18.5)$ & \\
\hline Change regimen & $4(1.1)$ & $22(14.0)$ & & $1(0.7)$ & $7(4.6)$ & \\
\hline Best response ${ }^{c}$ & & & 0.33 & & & 0.29 \\
\hline$C R$ & $4(1.1)$ & $0(0)$ & 0.18 & $3(2.0)$ & $0(0)$ & \\
\hline PR & $106(28.9)$ & $48(32.4)$ & & $48(32.0)$ & $46(32.4)$ & \\
\hline SD & $166(45.2)$ & $71(48.0)$ & & $64(42.7)$ & $68(47.9)$ & \\
\hline PD & $91(24.8)$ & 29 (19.6) & & $35(23.3)$ & $28(19.7)$ & \\
\hline \multicolumn{7}{|l|}{ Response rates $^{c}$} \\
\hline ORR & $110(30.0)$ & $48(32.4)$ & 0.58 & $51(34.0)$ & $46(32.4)$ & 0.77 \\
\hline DCR & $276(75.2)$ & $119(80.4)$ & 0.21 & $115(76.7)$ & $114(80.3)$ & 0.45 \\
\hline Second-line treatment & $245(69.2)$ & $92(58.6)$ & 0.02 & $103(71.5)$ & $88(58.3)$ & 0.02 \\
\hline FOLFIRINOX & - & 61 & & - & 59 & \\
\hline Nab-paclitaxel & 120 & - & & 53 & - & \\
\hline Clinical trial & 33 & 5 & & 14 & 4 & \\
\hline Other Gemcitabine ${ }^{d}$ & 86 & 0 & & 34 & 0 & \\
\hline Other 5-FU & 6 & 26 & & 2 & 25 & \\
\hline \multicolumn{7}{|c|}{$\begin{array}{l}\text { FFX FOLFIRINOX, GnP gemcitabine plus nab-paclitaxel, } A E \text { s adverse events, } C R \text { complete } \\
\text { disease, ORR objective response rate, DCR disease control rate, 5-FU 5-fluorouracil, FOLF } \\
\text { leucovorin, iFAM infusional 5-FU plus doxorubicin and mitomycin-C } \\
\text { alncluded patients for whom nab-paclitaxel was omitted due to adverse events } \\
{ }^{b} \text { Discontinuation chemotherapy or switching of chemotherapy regimen } \\
{ }^{c} \text { Not evaluated for patients with regimen change or death before response evaluation } \\
{ }^{d} \text { Included gemcitabine single, gemcitabine plus erlotinib regimens } \\
\text { eIncluded FL, FOLFOX, FOLFIRI, iFAM, capecitabine plus oxaliplatin, tegafur/gimestat/ota }\end{array}$} \\
\hline
\end{tabular}

matching; both $P=0.02$ ). The proportion of FFX-GnP sequence and reverse sequence ( $\mathrm{GnP}-\mathrm{FFX})$ were not significantly different between the two groups. Treatment outcomes of sequential chemotherapy are presented in Table 3. There was no significant difference in ORR or DCR during second-line treatment. The rate of patients who underwent the third-line chemotherapy was not different between the two sequences. Regarding treatment efficacy, the median PFS was 12.7 months for the FFXGnP sequence and 14.1 months for the GnP-FFX sequence without showing significant difference between the two sequences (Fig. 3). The median OS was not significantly different according to the sequence either (Fig. 4). There was no significant difference in survival according to the sequence of treatment for several subgroups (age, ECOG-PS, and previous curative surgery) (Supplementary Fig. 5-7).

\section{Treatment-related adverse events in the whole} population and the matched population

Treatment-related AEs in the whole population and the matched population are shown in Table 4. Regarding hematologic toxicities, the $\mathrm{GnP}$ group had higher incidence of severe anemia (grade 3 to 4 ) before and after matching. The rate of febrile neutropenia occurred more frequently in the FFX group before matching $(12.9 \%$ vs. $6.4 \%, P=0.03)$, but not significantly different after matching $(P=0.30)$. Prophylactic granulocyte colonystimulating factor (G-CSF) was more frequently used in the FFX group $(P<0.001)$. With regard to peripheral neuropathy, more patients in the GnP group needed anti-neuropathic drugs or dose reduction to relieve their symptoms with significant difference before matching $(P<0.01)$, but nonsignificantly different $(P=0.07)$ after matching. 


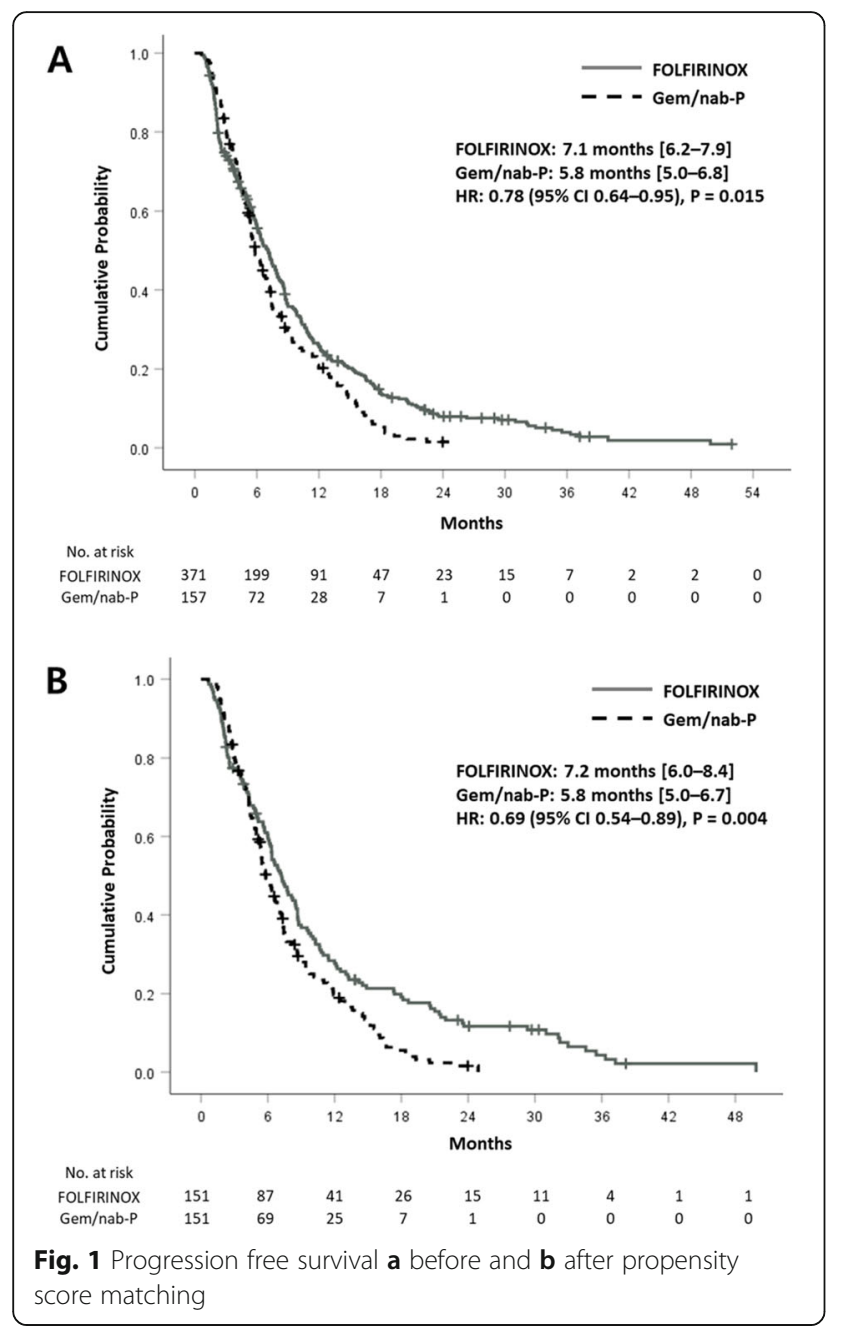

Causes of interruption chemotherapy due to AEs are listed in Table 4. Interruptions occurred significantly more in the GnP group as described above. General weakness (deterioration of performance) was the most common cause of in both groups, whereas peripheral neuropathy was another notable cause in the $\mathrm{GnP}$ group. Drug-induced pneumonitis and peripheral edema were observed only in patients of the GnP group.

\section{Discussion}

Current guidelines recommend FFX and GnP as firstline treatment regimens of $\mathrm{mPC}$ [7-9]. The present study showed an overall survival of 12 months in the FFX group and 10 months in the GnP group, in agreement with respective pivotal trials $[5,6]$. Statistical significance of survival in the FFX group was preserved even after PSM. In subgroups of patients with younger age, ECOG-PS 1+, and without a history of curative surgery, FFX treatment showed statistically significant survival benefits. With sequential treatment, the median OS was comparable between FFX-GnP (17 months) and

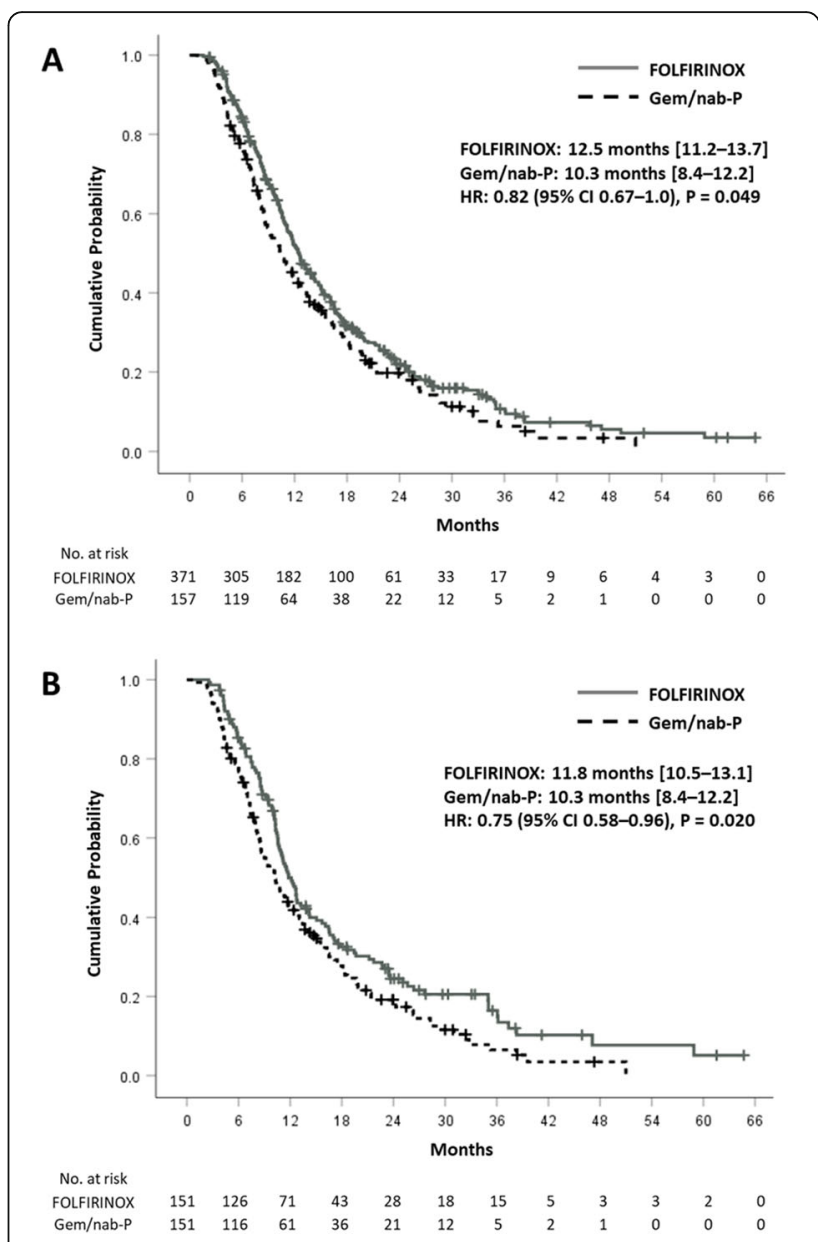

Fig. 2 Overall survival a before and $\mathbf{b}$ after propensity score matching

GnP-FFX (18 months) sequences in the whole population and the matched population. Regarding treatmentrelated AEs, febrile neutropenia occurred more frequently in the whole population, but not significantly different between the two groups in the matched population, whereas severe anemia and peripheral neuropathy occurred more frequently in the $\mathrm{GnP}$ group. Interruptions of chemotherapy due to AEs occurred more frequently in patients who received GnP. Major causes of interruptions were performance deterioration and peripheral neuropathy.

A recent systematic review has compared efficacies of FFX and GnP as first-line treatment in $\mathrm{mPC}$ patients and found no difference in efficacy regarding the risk of death and disease progression between the two regimens despite a numerical difference in OS (mean difference: $1.15 ; P=0.03)$ in favor of FFX [12]. And three recent published retrospective studies have also compared FFX and GnP in mPC patients (Supplementary Table 2) [1719]. Among these, two studies have shown superior OS for patients treated with FFX $[17,19]$. They performed 
Table 3 Treatment outcomes in patients with each sequential chemotherapy

\begin{tabular}{|c|c|c|c|c|c|c|}
\hline & FFX-GnP $(n=120)$ & GnP-FFX $(n=61)$ & $P$ value & FFX-GnP $(n=53)$ & GnP-FFX $(n=59)$ & $P$ value \\
\hline Treatment duration (months) & $12.0(7.6-18.1)$ & $11.7(7.6-19.4)$ & 0.945 & $12.0(8.0-22.3)$ & $11.7(7.4-20.0)$ & 0.714 \\
\hline Best response in second-line treatment & & & 0.86 & & & 0.69 \\
\hline$C R$ & $1(0.8)$ & $0(0)$ & & $1(1.9)$ & $0(0)$ & \\
\hline PR & $19(15.8)$ & $10(16.4)$ & & $7(13.2)$ & $10(16.9)$ & \\
\hline SD & $61(50.8)$ & $29(47.5)$ & & $27(50.9)$ & $28(47.5)$ & \\
\hline PD & $39(32.5)$ & $22(36.1)$ & & $18(34.0)$ & $21(35.6)$ & \\
\hline \multicolumn{7}{|l|}{ Response rates in second-line treatment } \\
\hline DCR & $81(67.5)$ & $39(63.9)$ & 0.631 & $35(66.0)$ & $38(64.4)$ & 0.86 \\
\hline ORR & $20(16.7)$ & $10(16.4)$ & 0.963 & $8(15.1)$ & $10(16.9)$ & 0.79 \\
\hline Third-line chemotherapy & $47(39.2)$ & $29(47.5)$ & 0.508 & $16(30.2)$ & $28(47.5)$ & 0.14 \\
\hline Other $5-\mathrm{FU}^{\mathrm{a}}$ & 46 & 6 & & 1 & 6 & \\
\hline Other gemcitabine ${ }^{b}$ & 1 & 21 & & 15 & 20 & \\
\hline Other (clinical trial, SBRT) & 0 & 2 & & 0 & 2 & \\
\hline
\end{tabular}

FFX FOLFIRINOX, GnP gemcitabine plus nab-paclitaxel, $A E s$ adverse events, $C R$ complete response, $P R$ partial response, $S D$ stable disease, $P D$ progression of disease, ORR objective response rate, DCR disease control rate, 5-FU 5-fluorouracil, SBRT stereotactic body radiotherapy, NAPOLI nanoliposomal irinotecan plus 5$\mathrm{FU} /$ lecovorin, iFAM infusional 5-FU plus doxorubicin and mitomycin-C

ancluded the NAPOLI, iFAM, tegafur/gimestat/otastat potassium, capecitabine, and CCRT with 5-FU or capecitabine regimens

${ }^{\mathrm{b}}$ Included gemcitabine, gemcitabine plus erlotinib

propensity score analysis to reduce the bias due to confounding variables such as age, sex, ECOS-PS, and so on known to be import prognostic factors of survival [16]. We also performed PSM to lower differences in baselines between the two groups. After PSM, the significance of survival benefit by FFX as first-line chemotherapy was statistically reinforced (from $P=0.05$ to $P=0.02$ ). Regarding response rate, ORR and DCR of the $\mathrm{GnP}$ were not significantly different from those of the FFX group as first- and second-line treatments including their sequential treatment.

FFX is usually preferred for younger patients in good performance status [12]. In this study, FFX also showed favorable survival in the subgroup of patients under age 65. However, OS in patients with ECOG-PS 0 showed no significant different between the two regimens. ECOG-PS did not show prognostic significance for OS in the proportional hazards model. Rather, cessation chemotherapy among interruptions was significantly associated with poor survival. The proportion of interruption of chemotherapy due to AEs was significantly higher in the GnP regimen. The main cause of interruption was deterioration of performance status. A previous study has also reported that the rate of cessation chemotherapy due to AEs was (nonsignificantly) higher in the GnP group (14\% vs. $21 \%)$ with general weakness being the main cause of early-termination of chemotherapy [18]. These interruptions might account for the result of a shorter treatment duration in the GnP group in this study despite no difference in follow-up period (33 months in the FFX group vs. 32 months in the GnP group, $P=0.91)$. It was confirmed that the median OS was longer in the patients with FFX who had interruptions, especially cessation of chemotherapy (Supplementary Fig. 8-9).

Performance status decline due to GnP could also explain the result that FFX treatment rather reduced the risk of death in patients with ECOG-PS $1+$ in the subgroup analysis. In this subgroup, the incidence rate of cessation chemotherapy was much higher $(17.9 \%$ vs. $5.5 \%, P<0.001)$ in the GnP group compared to the result of the whole population. In another aspect of tolerability, dose modification was more frequently in FFX group. The efficacy and tolerability of FFX with modified dose for unresectable PC demonstrated in several studies [20, 21]. Modified FFX showed comparable survival outcomes compared to full dose regimen and less adverse events [20]. Appropriate dose modification and tolerance to chemotherapy would provide patients with more chances for second-line treatment, and more patients in the FFX group received second-line chemotherapy in this study.

Peripheral neuropathy is another notable cause of interruption chemotherapy in this study. Chemotherapyinduced peripheral neuropathy could be experienced by patients receiving both $\mathrm{GnP}$ (due to nab-paclitaxel) and FFX (due to oxaliplatin) regimens. In our results, however, significantly more patients suffered from neuropathy during $\mathrm{GnP}$ treatment and regimen change was more needed even if chemotherapy kept the tumor under control. In this regard the high probability of neuropathy development should be carefully taken into account when determining treatment with GnP. Further study is needed to reveal factors associated with the 


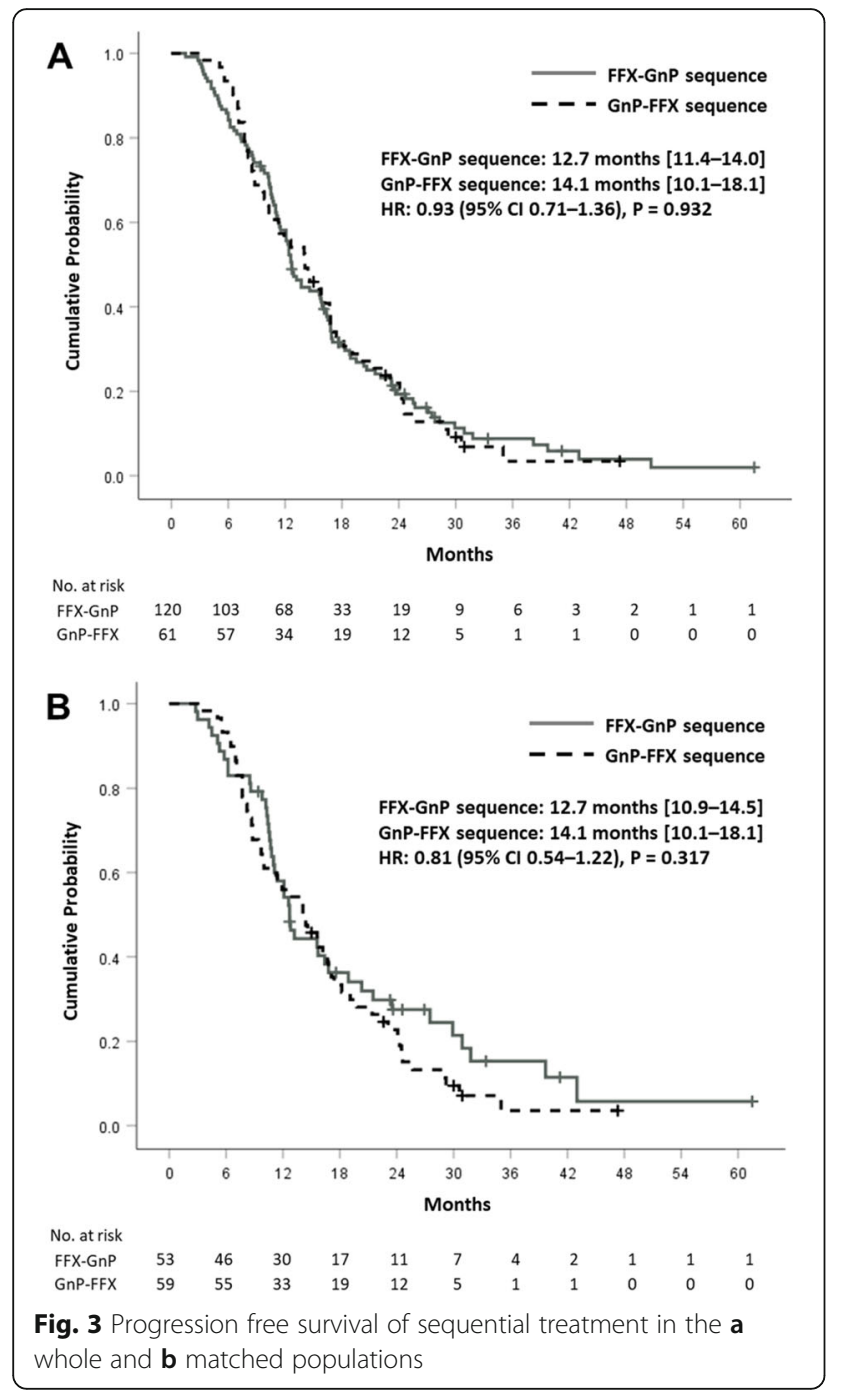

occurrence of GnP-induced neuropathy. Another concerned $\mathrm{AE}$ of chemotherapy was bone marrow suppression. Although neutropenia and febrile neutropenia are well-known AEs of FFX, there was no significant difference in the incidence of neutropenia or febrile neutropenia in the matched population in our results. This might be related to the predominantly higher use of prophylactic G-CSF in the FFX group. A similar result has been shown in a recent retrospective comparative study in Korea [18]. Conversely, another result of marrow suppression, severe anemia, was more frequent in the GnP group, in accordance with previous metaanalysis results [12]. Different patterns and severity of AEs between two regimens showed in this study, but the mechanism of theses difference was not elucidated. Translational research, for example genome- or transcriptome-based comparison, would illuminate the factors associated with susceptibility to AEs, and targeting strategies could be used in clinical applications to

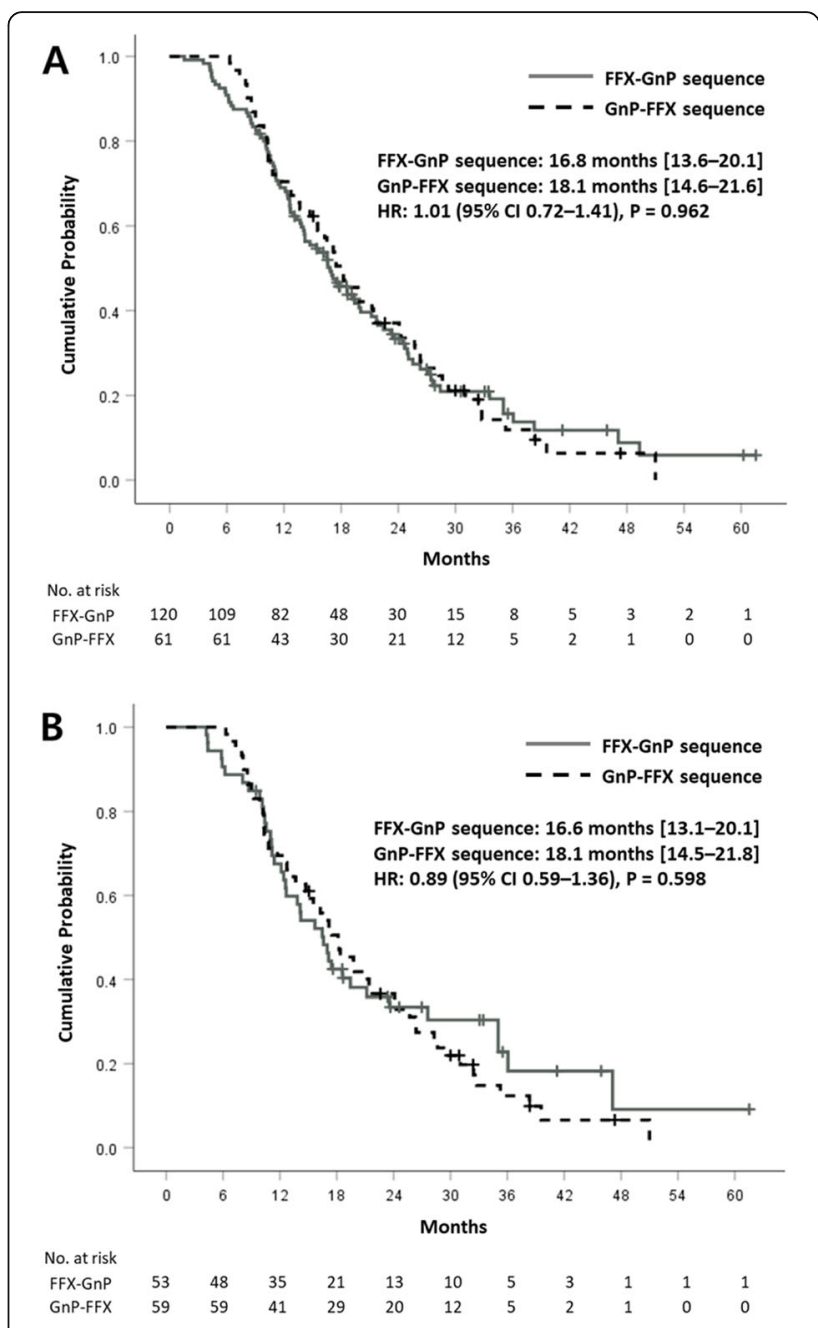

Fig. 4 Overall survival of sequential treatment in the $\mathbf{a}$ whole and $\mathbf{b}$ matched populations

reduce interruptions of chemotherapy and improve survival outcomes $[22,23]$.

With improved survival of pancreatic cancer in the last few decades, treatment sequences also became a factor to consider in chemotherapy. In the present data, both PFS and OS were comparable between FFX-GnP and GnP-FFX sequences. There was no significant difference in subgroup survival analyses. Response rates were not significantly different across each line of treatment in two sequences. Several studies have compared OS between two subsequent treatments and found no significant difference in survival benefit $[17,19,24]$. Williet et al. have assessed the feasibility of two sequences through the proportion of each sequence (43\% in FFXGnP vs. $13 \%$ in GnP-FFX) [17]. Although the rate of second-line FFX after GnP (32.3\%) was comparable to that of GnP after FFX (38.9\%) in our study, the proportion of patients who received second-line treatment was significantly higher in the FFX first group. Therefore, 
Table 4 Treatment-related adverse events and causes of chemotherapy interruptions

\begin{tabular}{|c|c|c|c|c|c|c|}
\hline & $\begin{array}{l}\text { FOLFIRINOX } \\
(n=371)\end{array}$ & $\begin{array}{l}\text { Gemcitabine/nab- } \\
\text { paclitaxel }(n=157)\end{array}$ & $P$ value & $\begin{array}{l}\text { FOLFIRINOX } \\
(n=151)\end{array}$ & $\begin{array}{l}\text { Gemcitabine/nab- } \\
\text { paclitaxel }(n=151)\end{array}$ & $P$ value \\
\hline \multicolumn{7}{|l|}{ Treatment-related adverse events } \\
\hline Anemia $\geq 3$ & $70(18.9)$ & $50(31.8)$ & $<0.01$ & $29(19.2)$ & $50(33.1)$ & 0.01 \\
\hline Thrombocytopenia $\geq 3$ & $48(12.9)$ & $15(9.6)$ & 0.27 & $22(14.6)$ & $15(9.9)$ & 0.22 \\
\hline Neutropenia $\geq 3$ & $181(48.8)$ & $70(44.6)$ & 0.38 & $78(51.7)$ & $67(44.4)$ & 0.21 \\
\hline Neutropenic fever & $48(12.9)$ & $10(6.4)$ & 0.03 & $15(9.9)$ & $10(6.6)$ & 0.30 \\
\hline $\begin{array}{l}\text { Granulocyte colony } \\
\text { stimulating factor }\end{array}$ & $304(81.9)$ & $10(6.4)$ & $<0.001$ & $130(86.1)$ & $9(6.0)$ & $<0.001$ \\
\hline Peripheral neuropathy & $56(15.1)$ & $40(25.5)$ & $<0.01$ & 25 (16.6) & $38(25.2)$ & 0.07 \\
\hline $\begin{array}{l}\text { Cause of chemotherapy } \\
\text { interruption }\end{array}$ & $25(6.7)$ & $46(29.3)$ & $<0.001$ & $12(7.9)$ & $35(23.2)$ & $<0.001$ \\
\hline General weakness & $21(5.6)$ & $22(14.0)$ & & $10(6.6)$ & 19 (12.6) & \\
\hline Peripheral neuropathy & 0 & $15(9.6)$ & & 0 & $8(5.3)$ & \\
\hline Peripheral edema & 0 & $3(1.9)$ & & 0 & $3(2.0)$ & \\
\hline Uncontrolled diarrhea & $1(0.3)$ & $1(0.6)$ & & 0 & $1(0.7)$ & \\
\hline Drug-induced pneumonitis & 0 & $2(1.3)$ & & 0 & $1(0.7)$ & \\
\hline Bone marrow suppression & $3(0.8)$ & $1(0.6)$ & & $2(1.3)$ & $1(0.7)$ & \\
\hline $\begin{array}{l}\text { Others (pneumonia, tumor } \\
\text { bleeding) }\end{array}$ & 0 & $2(1.3)$ & & 0 & $2(1.4)$ & \\
\hline
\end{tabular}

when considering the efficacy, feasibility, and AEs (especially, deterioration of performance and peripheral neuropathy), FFX as the first-line treatment could be a better choice of chemotherapeutic regimen.

The main limitation of this study came from its retrospective design. Hence, exact data could not be obtained. We performed PSM with a relatively large number of patients to alleviate potential confounders. Standardized mean differences were lesser than $10 \%$ after matching which confirmed that our data were well-balanced [13]. The absence of comparing the cost-effectiveness analysis of two regimens was another limitation. Cho et al. have shown that costs of these two regimens are not very different for first-line setting [18]. However, second-line FFX or GnP is not covered under national health insurance system in Korea. This should be considered in determining the sequential treatment. Randomized controlled trials are warranted to clarify which regimen or sequence of the two regimens would be beneficial to patients with $\mathrm{mPC}$. Our results showed the survival benefit of FFX first treatment, and the main explanation is different tolerance to chemotherapy. However, the biological mechanism was not elucidated, and the research using preclinical models of pancreatic cancer is needed to illuminate the biomolecular meaning of clinical findings.

One of the strengths of our study was that it had a relatively large number of patients compared to previous retrospective studies, even after PSM. Patient matching was well-performed with standardized mean differences under $10 \%$ and the survival benefit of FFX was maintained after matching. Therefore, this study would provide valid comparative results of two regimens and sequences in the absence of a randomized comparative study. We also suggested a possible explanation of survival benefit of FFX fist regimen, less interruptions of treatment (mainly cessation chemotherapy) due to AEs. However, if the reverse sequence can be performed through second-line therapy, there will be no significant difference in survival.

In conclusion, results of our study support the survival benefit of FFX as first-line treatment for mPC. Our results also showed comparable efficacy between two sequences. FFX first sequence would be tolerable in terms of a lower rate of interrupting chemotherapy due to AEs than GnP. However, even in cases of treatment with $\mathrm{GnP}$ as first-line regimen, second-line FFX would ensure comparable survival outcome in patients with adequate performance. Further studies are warranted to identify patients who are fit for each regimen and sequence. Further studies are also needed to illuminate risk factors for chemotherapy-related AEs in order to screen chemotherapy interruption due to AEs.

\section{Abbreviations}

PC: Pancreatic cancer; FFX: FOLFIRINOX; GnP: Gemcitabine plus nabpaclitaxel; mPC: Metastatic pancreatic cancer; ECOG-PS: Eastern Cooperative Oncology Group performance status; OS: Overall survival; PFS: Progression survival; FFX-GnP: FOLFIRINOX followed by sequential gemcitabine plus nab- 
paclitaxel; GnP-FFX: Gemcitabine plus nab-paclitaxel followed by sequential FOLFIRINOX; AE: Adverse event; PSM: Propensity score matching; ORR: Objective response rate; DCR: Disease control rate; Hb: Hemoglobin; IQR: Interquartile range; HR: Hazard ratio; $\mathrm{Cl}$ : Confidence interval

\section{Supplementary Information}

The online version contains supplementary material available at https://doi. org/10.1186/s12885-021-08277-7.

\section{Additional file 1: Supplementary Table 1. Uni-/multi-variable} analyses of prognostic factors for overall survival. Supplementary Table 2. Recently published studies comparing FOLFIRINOX vs Gemcitabine/nab-paclitaxel including sequential treatment.

Supplementary Figure 1. Subgroup analyses for overall survival in the (A) whole and (B) matched populations according to the first-line treatment regimens. Supplementary Figure 2. Kaplan-Meier curves of overall survival among patients with age $<65$ years in the (A) whole and (B) matched populations. Supplementary Figure 3. Kaplan-Meier curves of overall survival among patients with ECOG 1+ in the (A) whole and (B) matched populations. Supplementary Figure 4. Kaplan-Meier curves of overall survival among patients without previous pancreatic resection in the (A) whole and (B) matched populations. Supplementary Figure 5. Kaplan-Meier curves of overall survival in patients with sequential treatment according to patients' age. (A) Age $<65$ years; (B) Age $\geq 65$ years. Supplementary Figure 6. Kaplan-Meier curves of overall survival in patients with sequential treatment according to performance status. (A) ECOG-PS 0; (B) ECOG-PS 1. Supplementary Figure 7. Kaplan-Meier curves of overall survival in patients with sequential treatment according to history of pancreatic resection. (A) Naïve status; (B) With resection. Supplementary Figure 8. Kaplan-Meier curves of overall survival in patients with interruptions of chemotherapy (A) before matching and (B) after matching. Supplementary Figure 9. Kaplan-Meier curves of overall survival in patients with cessation of chemotherapy (A) before matching and (B) after matching

\section{Acknowledgements}

We would like to express our deepest gratitude to Dr. Ki Ho Yang and his colleague Myeong Hee Choi for their support on this research. And, we thanks to Prof. Jeong-Hoon Lee for his intellectual advice on the manuscript.

\section{Authors' contributions}

Study concepts and design were completed by S.H.L. Data acquisition was performed by J.W.C., J.S.K., P.N., G.H. Data analysis and interpretation were performed by I.R.C and W.H.P. Data analysis and interpretation, statistical analysis, manuscript preparation and editing were completed by all authors including J.K.R., YT.K. The manuscript was reviewed and approved by all authors.

\section{Funding}

Not applicable.

\section{Availability of data and materials}

The datasets used and/or analyzed during the current study are available from the corresponding author (Sang Hyub Lee) on reasonable request.

\section{Declarations}

\section{Ethics approval and consent to participate}

Formal consent was waived because of the retrospective nature or this study, and which was approved by the Institutional Review Board (IRB). IRB at Seoul National University Hospital (No. C-2009-058-1155) approved the study. All individual-level data were anonymized and only available to authorized researchers. IRB approved and monitored safety and adequacy of data management. This study was performed in accordance with the Declaration of Helsinki.

\section{Consent for publication}

Not applicable.

\section{Competing interests}

The authors declare no competing interests.

\section{Author details}

${ }^{1}$ Center for Liver and Pancreatobiliary Cancer, Research Institute and Hospital, National Cancer Center, Goyang, South Korea. ${ }^{2}$ Department of Internal Medicine and Liver Research Institute, Seoul National University Hospital, Seoul National University College of Medicine, Seoul, South Korea.

Received: 23 February 2021 Accepted: 29 April 2021

Published online: 11 May 2021

\section{References}

1. Rahib L, Smith BD, Aizenberg R, Rosenzweig AB, Fleshman JM, Matrisian LM. Projecting cancer incidence and deaths to 2030: the unexpected burden of thyroid, liver, and pancreas cancers in the United States. Cancer Res. 2014; 74(11):2913-21. https://doi.org/10.1158/0008-5472.CAN-14-0155.

2. Rawla P, Sunkara T, Gaduputi V. Epidemiology of pancreatic Cancer: global trends, etiology and risk factors. World J Oncol. 2019;10(1):10-27. https://doi. org/10.14740/wjon1166.

3. Burris HA 3rd, Moore MJ, Andersen J, Green MR, Rothenberg ML, Modiano $M R$, et al. Improvements in survival and clinical benefit with gemcitabine as first-line therapy for patients with advanced pancreas cancer: a randomized trial. J Clin Oncol. 1997;15(6):2403-13. https://doi.org/10.1200/JCO.1997.15. 6.2403 .

4. Saung MT, Zheng L. Current standards of chemotherapy for pancreatic Cancer. Clin Ther. 2017;39(11):2125-34. https://doi.org/10.1016/j.clinthera.201 7.08.015.

5. Conroy T, Desseigne F, Ychou M, Bouché O, Guimbaud R, Bécouarn Y, et al. FOLFIRINOX versus gemcitabine for metastatic pancreatic Cancer. N Engl J Med. 2011;364(19):1817-25. https://doi.org/10.1056/NEJMoa1011923.

6. Von Hoff DD, Ervin T, Arena FP, Chiorean EG, Infante J, Moore M, et al. Increased survival in pancreatic Cancer with nab-paclitaxel plus gemcitabine. N Engl J Med. 2013;369(18):1691-703. https://doi.org/10.1056/ NEJMoa1304369.

7. Ducreux M, Cuhna AS, Caramella C, Hollebecque A, Burtin P, Goéré D, et al. Cancer of the pancreas: ESMO clinical practice guidelines for diagnosis, treatment and follow-upt. Ann Oncol. 2015;26:v56-68.

8. Sohal DPS, Kennedy EB, Khorana A, Copur MS, Crane CH, Garrido-Laguna I. et al. Metastatic pancreatic Cancer: ASCO clinical practice guideline update. J Clin Oncol. 2018;36(24):2545-56. https://doi.org/10.1200/JCO.2018.78.9636.

9. Tempero MA. NCCN Guidelines Updates: Pancreatic Cancer. J Natl Compr Cancer Netw. 2019;17(5.5):603-5.

10. Martín AM, Hidalgo M, Alvarez R, Arrazubi V, Martínez-Galán J, Salgado M, et al. From first line to sequential treatment in the Management of Metastatic Pancreatic Cancer. J Cancer. 2018;9(11):1978-88. https://doi.org/1 $0.7150 /$ jca.23716.

11. Papneja N, Zaidi A, Chalchal H, Moser M, Tan K, Olson C, et al. Comparisons of outcomes of real-world patients with advanced pancreatic Cancer treated with FOLFIRINOX versus gemcitabine and nab-paclitaxel: a population-based cohort study. Pancreas. 2019;48(7):920-6. https://doi.org/1 0.1097/MPA.0000000000001340.

12. Pusceddu S, Ghidini M, Torchio M, Corti F, Tomasello G, Niger M, et al. Comparative effectiveness of gemcitabine plus nab-paclitaxel and FOLFIRINOX in the first-line setting of metastatic pancreatic Cancer: a systematic review and meta-analysis. Cancers (Basel). 2019;11(4):484. https:// doi.org/10.3390/cancers11040484.

13. Austin PC. An introduction to propensity score methods for reducing the effects of confounding in observational studies. Multivar Behav Res. 2011; 46(3):399-424. https://doi.org/10.1080/00273171.2011.568786.

14. Shuster JJ. Median follow-up in clinical trials. J Clin Oncol. 1991;9(1):191-2. https://doi.org/10.1200/JCO.1991.9.1.191.

15. Tas F, Sen F, Keskin S, Kilic L, Yildiz I. Prognostic factors in metastatic pancreatic cancer: older patients are associated with reduced overall survival. Mol Clin Oncol. 2013;1(4):788-92. https://doi.org/10.3892/mco.2 013.131.

16. Tabernero J, Chiorean EG, Infante JR, Hingorani SR, Ganju V, Weekes C, et al. Prognostic factors of survival in a randomized phase III trial (MPACT) of weekly nab-paclitaxel plus gemcitabine versus gemcitabine alone in patients with metastatic pancreatic cancer. Oncologist. 2015;20(2):143-50. https://doi.org/10.1634/theoncologist.2014-0394. 
17. Williet N, Saint A, Pointet A-L, Tougeron D, Pernot S, Pozet A, et al. Folfirinox versus gemcitabine/nab-paclitaxel as first-line therapy in patients with metastatic pancreatic cancer: a comparative propensity score study. Ther Adv Gastroenterol. 2019:12:1756284819878660.

18. Cho IR, Kang H, Jo JH, Lee HS, Chung MJ, Park JY, et al. FOLFIRINOX vs gemcitabine/nab-paclitaxel for treatment of metastatic pancreatic cancer: single-center cohort study. World J Gastrointest Oncol. 2020;12(2):182-94. https://doi.org/10.4251/wjgo.v12.i2.182.

19. Chan KKW, Guo H, Cheng S, Beca JM, Redmond-Misner R, Isaranuwatchai W, et al. Real-world outcomes of FOLFIRINOX vs gemcitabine and nabpaclitaxel in advanced pancreatic cancer: a population-based propensity score-weighted analysis. Cancer Med. 2020;9(1):160-9. https://doi.org/10.1 002/cam4.2705.

20. Cavanna L, Stroppa EM, Citterio C, Mordenti P, Di Nunzio C, Peveri S, et al. Modified FOLFIRINOX for unresectable locally advanced/metastatic pancreatic cancer. A real-world comparison of an attenuated with a full dose in a single center experience. Onco Targets Ther. 2019;12:3077-85. https://doi.org/10.2147/OTT.S200754.

21. Wang ZQ, Zhang F, Deng T, Zhang L, Feng F, Wang FH, et al. The efficacy and safety of modified FOLFIRINOX as first-line chemotherapy for Chinese patients with metastatic pancreatic cancer. Cancer Commun (Lond). 2019; 39(1):26. https://doi.org/10.1186/s40880-019-0367-7.

22. Chien W, Sudo M, Ding LW, Sun QY, Wuensche P, Lee KL, et al. Functional genome-wide screening identifies targets and pathways sensitizing pancreatic Cancer cells to Dasatinib. J Cancer. 2018;9(24):4762-73. https:// doi.org/10.7150/jca.25138.

23. Pandya G, Kirtonia A, Sethi G, Pandey AK, Garg M. The implication of long non-coding RNAs in the diagnosis, pathogenesis and drug resistance of pancreatic ductal adenocarcinoma and their possible therapeutic potential. Biochim Biophys Acta Rev Cancer. 2020;1874(2):188423.

24. Vogl UM, Andalibi H, Klaus A, Vormittag L, Schima W, Heinrich B, et al. Nabpaclitaxel and gemcitabine or FOLFIRINOX as first-line treatment in patients with unresectable adenocarcinoma of the pancreas: does sequence matter? BMC Cancer. 2019;19(1):28. https://doi.org/10.1186/s12885-018-5240-6.

\section{Publisher's Note}

Springer Nature remains neutral with regard to jurisdictional claims in published maps and institutional affiliations.

Ready to submit your research? Choose BMC and benefit from:

- fast, convenient online submission

- thorough peer review by experienced researchers in your field

- rapid publication on acceptance

- support for research data, including large and complex data types

- gold Open Access which fosters wider collaboration and increased citations

- maximum visibility for your research: over $100 \mathrm{M}$ website views per year

At $\mathrm{BMC}$, research is always in progress.

Learn more biomedcentral.com/submissions 